\title{
Are pregnant women with chronic helminth infections more susceptible to congenital infections?
}

\author{
Amir Abdoli ${ }^{1,2 *}$ and Majid Pirestani ${ }^{2}$ \\ ' Department of Parasitology, Faculty of Medical Sciences, Kashan University of Medical Science, Kashan, Iran \\ 2 Department of Parasitology, Faculty of Medical Sciences, Tarbiat Modares University, Tehran, Iran \\ *Correspondence: a.abdoli@modares.ac.ir; a.abdoli25@gmail.com \\ Edited by: \\ Abhay Satoskar, The Ohio State University, USA \\ Reviewed by: \\ Luis I. Terrazas, Unidad de Investigación en Biomedicina, Mexico \\ Jorge Morales-Montor, Universidad Nacional Autónoma de México, Mexico
}

Keywords: pregnancy, helminth infections, congenital infections, immune response, intracellular pathogens, T-helper 1, T-helper 2, immunoregulation

\section{SOME SIMILARITIES BETWEEN IMMUNE RESPONSE DURING PREGNANCY AND CHRONIC HELMINTH INFECTIONS EXIST}

Pregnancy is a unique immunological status with different hormonal and immunological alterations. Pregnancy hormones (including progesterone, glucocorticoids, estradiol, and estriol) increase over the course of pregnancy and significantly modulate the immunological shift that occurs over the three trimesters of pregnancy (1). In contrast, helminth infections are the most common infectious diseases in developing countries. Soiltransmitted helminths (ascariasis, trichuriasis, and hookworm), schistosomiasis, and lymphatic filariasis are the most common helminthiasis. Most helminth infections have minor clinical symptoms; thus, the infection is left untreated and may remain chronic for multiple years (2).

It is well-documented that a woman's immune response during pregnancy and chronic helminth infections shift toward Type 2 immunity and anti-inflammatory cytokines (1,3-6). During pregnancy, the activities of $\mathrm{CD} 4+\mathrm{T}$ cells into helper $\mathrm{T}$ cell type 2 (Th2) and their anti-inflammatory cytokines [including interleukin-4 (IL-4), IL-5, and IL-10] increase. Inversely, the activities of T-helper 1 (Th1) cells and their inflammatory cytokines [as well as inflammatory macrophages and natural killer (NK) cells] decrease (1). These immunological shifts away from inflammatory responses are necessary for a successful pregnancy $(1,3)$. For example, activating cytotoxic cells (including NK or T cells and inflammatory cytokines such as
IFN- $\gamma$ and TNF- $\alpha$ ) can damage the placenta and fetus (3). Moreover, the elevation of anti-inflammatory factors like IL-10 can prevent spontaneous abortions in murine models (7).

Similar to immune response during pregnancy, the immune response during a helminth infection shifts toward Th2 and anti-inflammatory status. During chronic helminth infections, the increased activation and expansion of CD4+ Th2 cells (including eosinophils, mast cells, basophils, and the antibody isotypes IgG1, IgG4, and IgE) occur. Moreover, production of the cytokines IL-4, IL-5, IL-9, IL-10, IL-13, and IL-21 and transforming growth factor- $\beta$ (TGF- $\beta$ ) increases (4, 5). On the other hand, several studies in murine models reveal that helminth infections manipulate host hormones for its own benefit [reviewed in Ref. (8)]. In the case of Taenia crassiceps infection (a model for human cysticercosis), infected female mice showed an increase estrogen levels after 8 weeks post-infection. Infected male also showed increase serum estradiol and decrease testosterone levels. These hormonal changes lead to increase parasite density in both genders (9). Progesterone treatment in mice with T. crassiceps infection increased parasite loads and expression of the Th2 cytokine profile (IL-4, IL-6, and IL-10) in both genders (10). These findings reveal that female sex hormones are favorable for T. crassiceps infection and the infection is associated with Type 2 immunity. Hormonal regulation during helminth infections is often associated with increased parasite survival and Type 2 immunity [reviewed in Ref.
$(11,12)]$, which negatively affect immune response to intracellular pathogens.

In contrast to immune response during pregnancy and chronic helminth infections, the protective immune response against the majority of the intracellular pathogens are mediated by Th1 cells and their cytokines (including IFN- $\gamma$, TNF$\alpha$, and IL-1) (13). Furthermore, increased activation and expansion of cytotoxic CD8+ T cells, NK cells, neutrophils, and macrophages occur during infection with intracellular pathogens $(4,13)$.

Therefore, immune system during pregnancy or helminth infections gives a weaker response to the infections that require strong Th1 immune response. So, it is plausible that a pregnant woman with chronic helminth infections is more susceptible to acquiring congenital infections due to synergic immunoregulatory effects of pregnancy and chronic helminth infections (see the next sections).

\section{INCREASE IN SUSCEPTIBILITY AND SEVERITY TO INFECTIOUS DISEASES DURING PREGNANCY}

Immunological shifts toward Th2 response during pregnancy increases a woman's susceptibility and severity to several infectious diseases such as malaria, measles, influenza, and toxoplasmosis $(1,14,15)$. The results of a recent systematic review revealed that pregnant women are more susceptible to the acquisition of malaria, HIV infection, and listeriosis. Also, pregnancy increased the severity of malaria, influenza, hepatitis E, herpes simplex virus (HSV), measles, and smallpox (14). Thus, infectious diseases in pregnant women are 
more common and severe due to physiological immunoregulation that require for a successful pregnancy.

\section{INCREASES IN SUSCEPTIBILITY AND SEVERITY TO INFECTIOUS DISEASES DURING CHRONIC HELMINTH INFECTIONS}

Activation of Th2 immune responses and immunoregulatory pathways during helminth infections potentially downregulates the effector functions that mediate type 1 immune responses during intracellular pathogens; therefore, both the severity of and susceptibility to intracellular pathogens are increasing (16). Several studies support the finding that helminth infections modulate immune responses to HIV infection (16), Mycobacterium tuberculosis (16-18) and Plasmodium species (16, 19, 20). Eradication of helminth infections in HIV-positive patients significantly inhibits the progression of HIV infection by attenuation of the plasma viral load and increasing CD4 counts (21). The results of a randomized, double blind, placebo-controlled trial demonstrated that treatment of Ascaris lumbricoides infection in HIV-positive patients significantly increased CD4+ T cell counts and decreased viral load compared with placebo (22). Moreover, albendazole-treated patients had significantly lower plasma IL-10 levels (23). A study among Tanzanian women of reproductive age showed that the prevalence of HIV in women with urogenital schistosomiasis was threefold higher than women without urogenital schistosomiasis (24). Furthermore, it was observed that the densities of CD4+ $\mathrm{T}$ cells and macrophages in genital mucosa surrounding Schistosoma haematobium eggs were significantly higher than in cervicovaginal mucosa without ova $(p=0.034$ and $p=0.018$, respectively) (25). In the subject of helminthtuberculosis co-infections, Elias et al. (26) observed that individuals with helminth infections had significantly lower levels of IFN- $\gamma$ production to $M$. tuberculosis antigens compared with the albendazoletreated group. Helminth co-infections also impaired efficient host immune responses to different bacterial pathogens (2732) as well as to Leishmania spp (33, 34) and Toxoplasma gondii (35). Therefore, immunoregulation during chronic helminth infections provides a suitable circumstance for acquisition of several infectious diseases.

\section{INCREASED RISK OF CONGENITAL INFECTIONS IN PREGNANT WOMEN WITH CHRONIC HELMINTH INFECTIONS}

As mentioned above, both pregnancy and chronic helminth infections increase susceptibility and severity toward the intracellular pathogens due to downregulation of type 1 immune response. This condition raises an important question: do the pregnancy and chronic helminth infections have synergic immunoregulatory effects? If this hypothesis is correct, pregnant women with chronic helminth infections may be more susceptible to congenital infections. However, there are some studies conducted in this regard (Table S1 in Supplementary Material). As reported by Gallagher et al. (36), helminth infections increase the risk of mother-to-child transmission of HIV infection. HIV-positive pregnant mothers with chronic helminth co-infection were found to have sevenfold greater risk of HIV transmission to their offspring $(\mathrm{OR}=7.3$, 95\% CL 2.433.7). Moreover, the increased risk of HIV transmission was significantly associated with higher production of IL-5/IL-13 by cord blood lymphocytes $(p<0.001)$ (36). The results from a randomized, placebocontrolled trial among HIV-positive pregnant women in Uganda showed that hookworm and Trichuris infections were significantly associated with increased HIV viral load during pregnancy. Moreover, when treated with albendazole, some experienced reduced viral load within 6 weeks after treatment (37). The results of a cross-sectional study in HIV-positive pregnant women in Rwanda revealed that the prevalence of soil-transmitted helminths was $38 \%$, malaria was $21 \%$, and malaria-helminth co-infection was $10 \%$. Also, helminth infections were associated with lower levels of hemoglobin and CD4 counts in HIV-positive mothers (38).

It has been proven the efficient vaccine against intracellular infections requiring cellular immunity and Th1 components (39). There is also evidence that maternal helminth infections suppress immune response to postnatal immunization (40).
Elliott et al. (41) observed that maternal hookworm infection was associated with reduced maternal IFN $-\gamma$ responses to crude culture filtrate proteins (CFP) of M. tuberculosis. Interestingly, an increase IFN- $\gamma$, in response to CFP, was found in mothers who were treated with albendazole, but not in untreated mothers. Conversely, lower levels of IFN- $\gamma$, in response to CFP, was observed in infants of hookworm-infected mothers who were treated with albendazole compared to those mothers receiving a placebo (41). It was also observed that the offspring of mothers infected with a filarial worm (Mansonella perstans) had higher levels of IL-10, in responses to CFP, and tetanus toxoid (42). Webb et al. (43) observed that albendazole therapy during pregnancy was associated with lower levels of IL-5 and IL-13 responses to tetanus toxoid in infants of mothers with hookworm infection (see details in Table S1 in Supplementary Material) (43).

Other studies were conducted in the area of malaria-helminth co-infection during pregnancy $(20,44-48)$. A recent metaanalysis by Naing et al. (20) revealed that pregnant women with hookworm infection had 1.36 times (OR: 1.36; 95\% CI: 1.17-1.59) higher risk of malaria infection than those mothers without hookworm infection. Moreover, the risk of malaria in primigravid mothers with soiltransmitted helminth infections was 1.6 times (OR: 1.61; 95\% CI: 1.3-1.99) higher than multigravid mothers (20). The results of a cross-sectional study among pregnant women in Ghana showed that mothers with intestinal helminth infections were at 4.8 times higher risk of acquiring Plasmodium falciparum infection (47). A study among pregnant women in Uganda demonstrated that women with hookworm and $M$. perstans infections had higher risk of $P$. falciparum infection (44). The odds ratio for $P$. falciparum infection in mothers infected with hookworm was 1.53 (CI, 1.09-2.14), for mothers infected with $M$. perstans 2.33 (CI, 1.47-3.69) and for mothers infected with both hookworm and $M$. perstans 1.85 (CI, 1.242.76) (44). Moreover, the study showed that the offspring of mothers with hookworm and $M$. perstans infections during pregnancy had significantly higher rates of clinical malaria and asymptomatic parasitemia in comparison with the 
children of uninfected mothers (45). It was also observed that quarterly albendazole therapy during childhood was associated significantly with the reduced incidence of clinical malaria (see details in Table S1 in Supplementary Material) (46). Henceforth, concurrent of helminth infections and pregnancy have serious consequences on mothers and their offspring; including increase susceptibility, severity, and the risk of mother-to-child transmission of intracellular pathogens, as well as immune response impairment to postnatal immunization.

\section{HELMINTH INFECTIONS, MALNOURISHMENT AND IMMUNE RESPONSE DURING PREGNANCY: ANOTHER COMPLICATION OF PREGNANT WOMEN WITH HELMINTH INFECTIONS}

It should be noted that most of the studies described above are coming from developing countries with poor nutrition status. Without adequate nutrition, immune system fails to produce an effective response to infections (49). On the other hand, helminth infections are more prevalent in developing countries with poor sanitation. Conversely, helminth infections are a cause of malnutrition and immune system impairment (50). In this complex situation, pregnant women with helminth infections may be more susceptible to acquiring of congenital infections due to the synergic immunoregulatory effects of malnutrition, pregnancy, and helminth infections.

As described above, pregnant women with chronic helminth infections are more susceptible to the acquisition and subsequent transmission of malaria (20,44-48) and HIV (36-38) infections to their offspring. It is also evident that helminth infection associations during pregnancy suppress immune responses to postnatal immunization (40-43).

In conclusion, the synergic immunoregulatory effects of pregnancy and chronic helminth infections offer a new insight into the role of immune response to intracellular pathogens. Therefore, increased susceptibility to several congenital infectious diseases - and their severity - are plausible. Hence, diagnosis and treatment of helminth infections in pregnant women should be given greater consideration.

\section{SUPPLEMENTARY MATERIAL}

The Supplementary Material for this article can be found online at http://www. frontiersin.org/Journal/10.3389/fimmu. 2014.00053/full

\section{REFERENCES}

1. Robinson DP, Klein SL. Pregnancy and pregnancy-associated hormones alter immune responses and disease pathogenesis. Horm Behav (2012) 62(3):263-71. doi:10.1016/j.yhbeh.2012. 02.023

2. Hotez PJ, Brindley PJ, Bethony JM, King CH, Pearce EJ, Jacobson J. Helminth infections: the great neglected tropical diseases. J Clin Invest (2008) 118(4):1311-21. doi:10.1172/JCI34261

3. Raghupathy R. Th 1-type immunity is incompatible with successful pregnancy. Immunol Today (1997) 18(10):478-82. doi:10.1016/S01675699(97)01127-4

4. Anthony RM, Rutitzky LI, Urban JF Jr, Stadecker MJ, Gause WC. Protective immune mechanisms in helminth infection. Nat Rev Immunol (2007) 7(12):975-87. doi:10.1038/nri2199

5. Allen JE, Maizels RM. Diversity and dialogue in immunity to helminths. Nat Rev Immunol (2011) 11(6):375-88. doi:10.1038/nri2992

6. Vargas-Villavicencio JA, León-Nava D, MoralesMontor J. Immunoendocrine mechanisms associated with resistance or susceptibility to parasitic diseases during pregnancy. Neuroimmunomodulation (2009) 16(2):114-21. doi:10.1159/000180266

7. Chaouat G, Meliani AA, Martal J, Raghupathy R, Elliott J, Elliot J, et al. IL-10 prevents naturally occurring fetal loss in the CBA x DBA/2 mating combination, and local defect in IL-10 production in this abortion-prone combination is corrected by in vivo injection of IFN-tau. J Immunol (1995) 154(9):4261-8.

8. Escobedo G, Roberts CW, Carrero JC, MoralesMontor J. Parasite regulation by host hormones: an old mechanism of host exploitation? Trends Parasitol (2005) 21(12):588-93. doi:10.1016/j.pt.2005. 09.013

9. Larralde C, Morales J, Terrazas I, Govezensky T, Romano MC. Sex hormone changes induced by the parasite lead to feminization of the male host in murine Taenia crassiceps cysticercosis. J Steroid Biochem Mol Biol (1995) 52(6):575-80. doi:10. 1016/0960-0760(95)00062-5

10. Vargas-Villavicencio JA, Larralde C, De León-Nava MA, Morales-Montor J. Regulation of the immune response to cestode infection by progesterone is due to its metabolism to estradiol. Microbes Infect (2005) 7(3):485-93. doi:10.1016/j.micinf.2004.12. 015

11. Morales-Montor J, Hall C. The host-parasite neuroimmunoendocrine network in schistosomiasis: consequences to the host and the parasite. Parasite Immunol (2007) 29(12):599-608. doi:10.1111/ j.1365-3024.2007.00968.x

12. Hernández Bello R, Escobedo G, Guzman C, Ibarra Coronado E, López Griego L, Morales-Montor J. Immunoendocrine host-parasite interactions during helminth infections: from the basic knowledge to its possible therapeutic applications. Parasite
Immunol (2010) 32(9-10):633-43. doi:10.1111/j. 1365-3024.2010.01232.x

13. Spellberg B, Edwards JE. Type 1/Type 2 immunity in infectious diseases. Clin Infect Dis (2001) 32(1):76-102. doi:10.1086/317537

14. Sappenfield E, Jamieson DJ, Kourtis AP. Pregnancy and susceptibility to infectious diseases. Infect Dis Obstet Gynecol (2013) 2013:752852. doi:10.1155/ 2013/752852

15. Jamieson DJ, Theiler RN, Rasmussen SA. Emerging infections and pregnancy. Emerg Infect Dis (2006) 12(11):1638-43. doi:10.3201/eid1211. 060152

16. Salgame P, Yap GS, Gause WC. Effect of helminthinduced immunity on infections with microbial pathogens. Nat Immunol (2013) 14(11):1118-26. doi:10.1038/ni.2736

17. Méndez-Samperio P. Immunological mechanisms by which concomitant helminth infections predispose to the development of human tuberculosis. Korean J Parasitol (2012) 50(4):281-6. doi:10. 3347/kjp.2012.50.4.281

18. Li X-X, Zhou X-N. Co-infection of tuberculosis and parasitic diseases in humans: a systematic review. Parasit Vectors (2013) 6(1):79. doi:10.1186/ 1756-3305-6-79

19. Knowles SC. The effect of helminth co-infection on malaria in mice: a meta-analysis. Int J Parasitol (2011) 41(10):1041-51. doi:10.1016/j.ijpara.2011. 05.009

20. Naing C, Whittaker MA, Nyunt-Wai V, Reid SA, Wong SF, Mak JW, et al. Malaria and soiltransmitted intestinal helminth co-infection and its effect on anemia: a meta-analysis. Trans $R$ Soc Trop Med Hyg (2013) 107(11):672-83. doi:10. 1093/trstmh/trt086

21. Walson JL, Herrin BR, John-Stewart G. Deworming helminth co-infected individuals for delaying HIV disease progression. Cochrane Database Syst Rev (2009) 3(3):CD006419. doi:10.1002/ 14651858.CD006419.pub3

22. Walson JL, Otieno PA, Mbuchi M, Richardson BA, Lohman-Payne B, Macharia SW, et al. Albendazole treatment of HIV-1 and helminth co-infection: a randomized, double-blind, placebo-controlled trial. AIDS (2008) 22(13):1601-9. doi:10.1097/ QAD.0b013e32830a502e

23. Blish CA, Sangaré L, Herrin BR, Richardson BA, John-Stewart G, Walson JL. Changes in plasma cytokines after treatment of Ascaris lumbricoides infection in individuals with HIV-1 infection. J Infect Dis (2010) 201(12):1816-21. doi:10.1086/ 652784

24. Downs JA, Mguta C, Kaatano GM, Mitchell KB, Bang H, Kalluvya SE, et al. Urogenital schistosomiasis in women of reproductive age in Tanzania's Lake Victoria region. Am J Trop Med Hyg (2011) 84(3):364-9. doi:10.4269/ajtmh.2011. 10-0585

25. Jourdan PM, Holmen SD, Gundersen SG, Roald B, Kjetland EF. HIV target cells in Schistosoma haematobium-infected female genital mucosa. Am J Trop Med Hyg (2011) 85(6):1060-4. doi:10.4269/ajtmh. 2011.11-0135

26. Elias D, Wolday D, Akuffo H, Petros B, Bronner U, Britton S. Effect of deworming on human $\mathrm{T}$ cell responses to mycobacterial antigens in helminth-exposed individuals before and after bacille Calmette-Guérin (BCG) vaccination. Clin 
Exp Immunol (2001) 123(2):219-25. doi:10.1046/ j.1365-2249.2001.01446.x

27. Du Y, Agnew A, Ye X, Robinson P, Forman D, Crabtree J. Helicobacter pylori and Schistosoma japonicum co-infection in a Chinese population: helminth infection alters humoral responses to $H$. pylori and serum pepsinogen I/II ratio. Microbes Infect (2006) 8(1):52-60. doi:10.1016/j. micinf.2005.05.017

28. Elsaied NA, Abbas AT, El-Beshbishi SN, Elsheikha HM. Increased Helicobacter pylori-associated pathology in outbred mice coinfected with schistosomiasis. Parasitol Res (2009) 105(2):297-9. doi: 10.1007/s00436-009-1486-x

29. Chen C-C, Louie S, McCormick B, Walker WA, Shi HN. Concurrent infection with an intestinal helminth parasite impairs host resistance to enteric Citrobacter rodentium and enhances Citrobacter-induced colitis in mice. Infect Immun (2005) 73(9):5468-81. doi:10.1128/IAI.73.9.54685481.2005

30. Su C-W, Cao Y, Zhang M, Kaplan J, Su L, Fu Y, et al. Helminth infection impairs autophagymediated killing of bacterial enteropathogens by macrophages. J Immunol (2012) 189(3):1459-66. doi:10.4049/jimmunol.1200484

31. Lass S, Hudson PJ, Thakar J, Saric J, Harvill E, Albert R, et al. Generating super-shedders: coinfection increases bacterial load and egg production of a gastrointestinal helminth. $J R$ Soc Interface (2013) 10(80):20120588. doi:10.1098/ rsif.2012.0588

32. Chen C-C, Louie S, McCormick BA, Walker WA, Shi HN. Helminth-primed dendritic cells alter the host response to enteric bacterial infection. J Immunol (2006) 176(1):472-83.

33. O'Neal SE, Guimarães LH, Machado PR, Alcântara L, Morgan DJ, Passos S, et al. Influence of helminth infections on the clinical course of and immune response to Leishmania braziliensis cutaneous leishmaniasis. J Infect Dis (2007) 195(1):142-8. doi:10.1086/509808

34. Hassan M, Zhang Y, Engwerda C, Kaye P, Sharp H, Bickle Q. The Schistosoma mansoni hepatic egg granuloma provides a favorable microenvironment for sustained growth of Leishmania donovani. Am J Pathol (2006) 169(3):943-53. doi:10. 2353/ajpath.2006.051319

35. Khan IA, Hakak R, Eberle K, Sayles P, Weiss LM, Urban JF. Coinfection with Heligmosomoides polygyrus fails to establish CD8+ Tcell immunity against Toxoplasma gondii. Infect Immun (2008) 76(3):1305-13. doi:10.1128/IAI 01236-07
36. Gallagher M, Malhotra I, Mungai PL, Wamachi AN, Kioko JM, Ouma JH, et al. The effects of maternal helminth and malaria infections on mother-to-child HIV transmission. AIDS (2005) 19(16):1849-55. doi:10.1097/01.aids.0000189846. $90946.5 \mathrm{~d}$

37. Webb EL, Kyosiimire-Lugemwa J, Kizito D, Nkurunziza P, Lule S, Muhangi L, et al. The effect of anthelmintic treatment during pregnancy on HIV plasma viral load: results from a randomized, double-blind, placebo-controlled trial in Uganda. J Acquir Immune Defic Syndr (2012) 60(3):307-13. doi:10.1097/QAI.0b013e3182511e42

38. Ivan E, Crowther N, Rucogoza A, Osuwat L, Munyazesa E, Mutimura E, et al. Malaria and helminthic co-infection among HIV-positive pregnant women: prevalence and effects of antiretroviral therapy. Acta Trop (2012) 124:179-84. doi:10. 1016/j.actatropica.2012.08.004

39. Seder RA, Hill AV. Vaccines against intracellular infections requiring cellular immunity. Nature (2000) 406(6797):793-8. doi:10.1038/35021239

40. LaBeaud AD, Malhotra I, King MJ, King CL, King $\mathrm{CH}$. Do antenatal parasite infections devalue childhood vaccination? PLoS Negl Trop Dis (2009) 3(5):e442. doi:10.1371/journal.pntd. 0000442

41. Elliott AM, Namujju PB, Mawa PA, Quigley MA, Nampijja M, Nkurunziza PM, et al. A randomised controlled trial of the effects of albendazole in pregnancy on maternal responses to mycobacterial antigens and infant responses to bacille CalmetteGuerin (BCG) immunisation [ISRCTN32849447]. BMCInfect Dis (2005) 5(1):115. doi:10.1186/14712334-5-115

42. Elliott AM, Mawa PA, Webb EL, Nampijja M, Lyadda N, Bukusuba J, et al. Effects of maternal and infant co-infections, and of maternal immunisation, on the infant response to BCG and tetanus immunisation. Vaccine (2010) 29(2):247-55. doi 10.1016/j.vaccine.2010.10.047

43. Webb EL, Mawa PA, Ndibazza J, Kizito D, Namatovu A, Kyosiimire-Lugemwa J, et al. Effect of single-dose anthelmintic treatment during pregnancy on an infant's response to immunisation and on susceptibility to infectious diseases in infancy: a randomised, double-blind, placebo-controlled trial. Lancet (2011) 377(9759):52-62. doi:10.1016/ S0140-6736(10)61457-2

44. Hillier SD, Booth M, Muhangi L, Nkurunziza P, Khihembo M, Kakande M, et al. Plasmodium falciparum and helminth coinfection in a semiurban population of pregnant women in Uganda. J Infect Dis (2008) 198(6):920-7. doi:10.1086/591183
45. Ndibazza J, Webb EL, Lule S, Harriet M, Akello M, Oduru G, et al. Associations between maternal helminth and malaria infections in pregnancy, and clinical malaria in the offspring: a birth cohort in Entebbe, Uganda. J Infect Dis (2013) 208(12):2007-16. doi:10.1093/infdis/jit397

46. Ndibazza J, Mpairwe H, Webb EL, Mawa PA, Nampijja M, Muhangi L, et al. Impact of anthelminthic treatment in pregnancy and childhood on immunisations, infections and eczema in childhood: a randomised controlled trial. PLoS One (2012) 7(12):e50325. doi:10.1371/journal. pone. 0050325

47. Yatich NJ, Yi J, Agbenyega T, Turpin A, Rayner JC, Stiles JK, et al. Malaria and intestinal helminth co-infection among pregnant women in Ghana: prevalence and risk factors. Am J Trop Med Hyg (2009) 80(6):896-901.

48. Thigpen MC, Filler SJ, Kazembe PN, Parise ME, Macheso A, Campbell $\mathrm{CH}$, et al. Associations between peripheral Plasmodium falciparum malaria parasitemia, human immunodeficiency virus, and concurrent helminthic infection among pregnant women in Malawi. Am J Trop Med Hyg (2011) 84(3):379-85. doi:10.4269/ajtmh.2011.100186

49. Cunningham-Rundles S, McNeeley DF, Moon A. Mechanisms of nutrient modulation of the immune response. J Allergy Clin Immunol (2005) 115(6):1119-28. doi:10.1016/j.jaci.2005.04.036

50. Hughes S, Kelly P. Interactions of malnutrition and immune impairment, with specific reference to immunity against parasites. Parasite Immunol (2006) 28(11):577-88. doi:10.1111/j.1365-3024. 2006.00897.x

Received: 14 November 2013; accepted: 29 January 2014; published online: 12 February 2014.

Citation: Abdoli A and Pirestani M (2014) Are pregnant women with chronic helminth infections more susceptible to congenital infections? Front. Immunol. 5:53. doi: 10.3389/fimmu. 2014.00053

This article was submitted to Microbial Immunology, a section of the journal Frontiers in Immunology.

Copyright $\odot 2014 \mathrm{Abdoli}$ and Pirestani. This is an openaccess article distributed under the terms of the Creative Commons Attribution License (CC BY). The use, distribution or reproduction in other forums is permitted, provided the original author(s) or licensor are credited and that the original publication in this journal is cited, in accordance with accepted academic practice. No use, distribution or reproduction is permitted which does not comply with these terms. 